\title{
Aphasia of Chinese Culture in Senior High School English Teaching-Taking a Key Middle School in Kunming as the Example
}

\author{
Dimin Luo \\ School of Foreign Languages \& Literature, Yunnan Normal University, Kunming, China. \\ Email: luodimin@163.com \\ Received May 27 ${ }^{\text {th }}$, 2011; revised June $15^{\text {th }}, 2011$; accepted June $22^{\text {nd }}, 2011$.
}

\begin{abstract}
Studies on aphasia of Chinese culture in college English teaching have been focused for a long time. Yet little attention has been paid to the senior high school English teaching concerning this problem. As a matter of fact, senior high school English teaching plays an essential role in English learning. In order to find out whether aphasia of Chinese culture exists in this stage and dig out the factors, the author has carried out a survey with quantitative and qualitative methods in the senior high school students of Grade one and teachers of a key middle school in Kunming. The survey reveals that this phenomenon does exist in senior high school English teaching and the extent is rather severe. The main reasons are lack of introduction on Chinese culture in English class, inadequacy of Chinese culture in textbooks and no emphasis on Chinese culture in English test. According to the explored reasons, the author proposes the corresponding suggestive solutions to the problem. They are: to reform the culture teaching, to add more Chinese culture in textbooks and to revise NMET (National Matriculation English Test).
\end{abstract}

Keywords: Aphasia of Chinese Culture, Senior High School English Teaching, Chinese Culture Education

\section{Introduction}

With the frequent contacts among different countries, intercultural communication is becoming more essential. Learning English is playing an important role in modern education. It has become a required course in both secondary and higher education in China. Mostly, the cultural content of English teaching is about the target culture, so students have become unfamiliar with their native culture, which means they are unable to express native culture in English well in intercultural communication.

Target culture is important in language learning, but it is not wise to neglect the expression of native culture. Through the comparison between two cultures, students can be more aware of the cultural identity. Samovar has pointed out that language usage and style reflect the personality of a culture in much the same way that they reflect the personality of an individual (Samovar, 2009). Thus the first way to make intercultural communication is to know one's own culture.

This paper aims at investigating the aphasia of Chinese culture in senior high school English education through exploring the issues on the existence of this phenomenon, the extent, the factors and the suggestive solutions to improve the cultural teaching in senior high school.

\section{Literature Review}

\section{Culture and Culture Teaching}

Culture has so far been defined by different scholars from different perspectives. But it always refers to some characteristics shared by a community, especially those which might dis- tinguish it from other communities (Hudson, 2007).

Culture is also classified in many ways. To distinguish between the culture of non-English-speaking countries and that of the English-speaking country, culture is divided into native culture and target culture (Zhang \& Zhang, 2007). Regarding this paper, it aims at investigating the phenomenon of students' aphasia of native culture, this classification is more proper.

Culture teaching plays an essential part of foreign language teaching in China Since 1960, culture has been emphasized. Many researchers and scholars have discussed the necessity of culture teaching in English teaching to help Chinese learners overcome pragmatic failures in intercultural communication. They have offered their ideas about culture teaching, which produced very good results. Besides, cultural awareness has been included in New English Curriculum Criteria for Senior School as one of the main five curriculum objectives in 2003. It requires that students should try to distinguish the differences and the similarities of Chinese cultures and foreign cultures to enhance the ability of intercultural communication (Ministry of Education, 2003).

Although culture teaching experienced its great development and improvement, culture teaching in China has predominantly focused on the teaching of target culture but ignored native culture. Consequently, many Chinese learners find it hard to conduct the effective intercultural communication. This unbalance culture teaching actually would make some obstacles in intercultural communication.

\section{Aphasia of Chinese Culture}

As a matter of fact, the unbalance culture teaching results in the aphasia of native culture. Aphasia is originally used as the 
disease in medical science. It refers to brain-generated defect in sounding words (Gao, 2006). In 1990s, Cao proposed the term "aphasia of Chinese literature" in face of the loss of Chinese literature (Cao, 1996). In China, it is Cong Cong who first cited this term in the teaching field in Guangming Daily. According to him, "aphasia of Chinese culture" means that in intercultural communication, students are incompetent in expressing Chinese culture in English, which is beneficial to neither students' overall development of communicative competence nor the successful and equal communication (Cong, 2000). After the publication of this article, more and more people are aware of this phenomenon. Some linguistic scholars in China have realized the importance of keeping a balanced teaching of target culture and native culture.

\section{Previous Studies on the Aphasia of Chinese Culture}

Concerning the previous studies, both theoretical studies and empirical studies have been done.

There are some essential theoretical studies in this field. Liu emphasized cultural teaching should balance native culture and target culture. He proposed some strategies for the integration of target culture and native culture (Liu, 2003). Gao brought forward "productive bilingualism" which can be represented by " $1+1>2$ ", as the incorporation of two languages and two cultures results in the fulfillment of creative potentials (Gao, 2001). Zhang et al. suggested "Productive Multiculturalism" to balance the diverse culture in English learning (Zhang, Mi, \& Sun, 2009). Zhang criticized three misunderstandings of intercultural communication to arise students' and teachers' attention to native culture (Zhang, 2009). Liu and He explored the post-orientation of localization in China from the perspective of globalization (Liu \& He, 2010).

There are also some significant empirical studies in this field. Deng and Ao investigated the aphasia of Chinese culture from the aspect of English majors and proposed some suggestions on the textbook, curriculum and the abilities of teachers (Deng \& Ao, 2005). However, their investigation lacked the students' participation. Zhang et al. took the notice of the aphasia of Chinese culture in non-English majors (Zhang, Mi, \& Yin, 2008). While, they only adopted the questionnaires to dig out the reason, which were not complete enough. Xiao et al. studied the current situation of the aphasia of Chinese culture in college by investigating the teaching management and revealed that Chinese culture teaching does not correspond to the college English syllabus (Xiao, Xiao, Li, \& Song, 2010).

The literature review indicates several gaps in terms of exploring of the issue on the aphasia of Chinese culture. Regarding subjects, most of studies focus on the higher education, and few studies have been touched on middle school education. For methods, most of the studies focus on the theoretical study and quantitative methods, but little work has combined both of them together to dig out the deeper and more specific reasons. As for the key materials - textbooks and NMET (National Matriculation English Test) papers, they are ignored by the scholars on this phenomenon.

According to the research gaps mentioned above, further research needs to complement them. Thus this paper studies this issue from the aspect of senior high school's context and focuses on Chinese culture in classroom instruction, textbooks and NMET papers to enhance the culture teaching in senior high school English class.

\section{Research Questions, Subjects, Methodology and Data Collection}

\section{Research Questions}

For the intentions of disclosing the problems underlying lack of native culture and providing countermeasures, the present study is designed to answer the following questions:

1) Does the aphasia of Chinese culture exist among senior high school students? If so, to what extent do the students "lose" their Chinese culture?

2) What's the arrangements of Chinese culture in English class?

3) What's the proportion of Chinese culture in English textbooks?

4) What's the proportion of Chinese culture in NMET papers?

\section{Subjects}

Subjects in this study: 1) 112 students from a key middle school in Kunming. All of them are senior high school students of Grade one, for they are not so busy to prepare the NMET. 2) 10 teachers from the same middle school in Kunming. 3) 5 required NSEFC (New Senior English for China) textbooks. 4) 5 NMET I papers 2006 to 2010.

\section{Methodology}

In order to make the investigation more comprehensive, both quantitative methods and qualitative methods are applied.

For the quantitative methods, questionnaires and test papers are adopted. They are adapted and revised according to Zhang Liyue (2009)'s, for her test papers and questionnaires are more proper. The test paper is for the students. The questionnaires are one for teachers and one for students. The test paper is designed to check whether the aphasia of Chinese culture exists among senior high school students and to what extent the students "lose" the native culture. It consists of twenty Chinese phrases which can typically reflect Chinese culture. All of them are required to be translated into English. There are 100 scores in all. The questionnaire for teachers includes ten multiple choices with four scales, $\mathrm{A}=$ strongly agree; $\mathrm{B}=$ agree; $\mathrm{C}=$ disagree; $\mathrm{D}$ = strongly disagree. The questionnaire for students also includes ten multiple choices with four scales.

As for qualitative methods, it includes observation of the class and document analysis. The observation lasts one month for 3 teachers' classes. It aims to dig out the more objective reasons. In doing this, the researcher does not let the teachers and students know anything about this research beforehand. Document analysis includes the analysis of textbooks and NMET I papers. The former concentrates on 5 required textbooks (NSEFC) published by People's Education Press to know the culture arrangements of the textbooks, especially the proportion and selection of Chinese culture in it. Since there are no special items for testing culture knowledge, the latter focuses on the culture carriers - the cloze and reading parts of NMET I papers 2006 to 2010 to see the proportion of Chinese culture in the papers.

\section{Data Collection}

Questionnaire and test paper investigations are applied after the class observation. For the questionnaires, 112 students and 
10 teachers were invited to finish. The students' valid questionnaires are 103; the teachers' valid questionnaires are 10. Concerning the test papers, 112 students are asked to finish. The valid test papers are 103. Thus, the investigation is valid enough. Before answering the test paper and questionnaires, the subjects had been told that the scores of the paper and the questionnaires had nothing to do with their other any achievements. Thus, their answers could be more objective and real.

As to the observation, it lasts one month from November to December in 2010. The researcher listened to 3 teachers' classes. When the author listened, she not only recorded the class but also made notes about the culture elements.

Concerning the textbooks and NMET papers, the author calculated the percentage of Chinese culture in the textbooks and NMET papers. The results are displayed in the form of tables.

\section{Data Analysis}

According to the data collected, this part is devoted to analyzing the results of the questionnaire, the test paper, the observation and the document analysis. First of all, the existence of the phenomenon will be examined. Secondly, the reason of this phenomenon will be analyzed according to the collected data.

\section{Existence of the Phenomenon}

As mentioned above, the test paper for student subjects are used to check whether the aphasia of Chinese culture exists among senior high school students. According to the scores of the test paper, the following bar graph is displayed with the help of Excel.

Figure 1 shows the panorama of students' ability of expressing Chinese culture in English. Students' scores of the whole test paper are rather low and even 60 scores is luxurious. These numbers apparently demonstrate the aphasia of Chinese culture does exist in senior high school English teaching and the extent is severe.

\section{Reason Analysis of Students' Chinese Culture’s Aphasia}

As stated above, the aphasia of Chinese culture exists in senior high school English education. Then, the following question comes: what the factors are responsible for this phenomenon? According to the investigation, three main factors have been dug out.

\section{Lack of Introduction on Chinese Culture in English Class}

Item 1 in students' and teachers' questionnaire asks about the difficulty of expressing Chinese culture. Table 1 has illustrated that $90 \%$ teachers and $94.18 \%$ students agree the degree of the difficulty in expressing Chinese culture in English is rather high.

To explore the reasons, the questionnaires also investigate the culture construction in EFL class as well as the means of getting culture knowledge. Item 8 in students' questionnaire asks about whether teachers often teach western culture in English class, and item 9 asks about whether teachers often teach Chinese culture in English class. The results of Table 2 show that their teachers often introduce the knowledge of English culture in class; however, the introduction of Chinese culture is rare.

Item 6 in teachers' questionnaire asks whether teachers themselves often introduce Chinese culture in English class. Table 3 shows that $90 \%$ teachers confess their introduction on Chinese culture is not enough.

During the observation, the researcher found the culture introduction usually concentrated on the leading in part which lasts 5 to 10 minutes. As for Chinese culture, if it appeared in the textbook, the teacher would extend a little; if there is no related introduction about Chinese culture, the teacher would not discuss it. In Table 4, it's clear that teachers spend plenty of time analyzing language points and exercise. That means they emphasize language forms in English study quite a lot.

From information above, it is concluded that there are some problems in terms of culture teaching. That is, there is not enough construction about native culture in English class. In a word, the lack of introduction on Chinese culture in class makes students feel difficult in expressing Chinese culture in English.

\section{Inadequacy of Chinese Culture in Textbooks}

Although there are many English teaching materials, the textbooks are the main source helping improve students' English. In addition, it is the textbooks that reflect the syllabus, the teaching and the learning. Therefore, textbooks play an important role in teachers' carrying out the teaching syllabus. Specifically, it is important for culture teaching.

In terms of the investigation about textbooks, item 7 and item 8 in teachers' questionnaire has been involved. Item 7 asks whether teachers feel it enough to apply the textbooks to finishing the cultural teaching and item 8 asks whether teachers think the textbooks have included adequate foreign and Chinese cultural materials. Table 5 shows most teachers do not think the textbooks could satisfy their cultural teaching needs and there is not enough introduction on Chinese culture in the textbooks.

In addition, Table 6 reveals that there is not adequate Chinese culture introduction in the five required textbooks from the more objective perspectives. Table 6 reports there is only $12 \%$ Chinese culture in the textbooks.

Thus, the inadequacy of teaching material in the textbooks is also responsible for students" "lose" the native culture.

\section{No Emphasis on Chinese Culture in English Test}

Tests are usually constructed as devices to reinforce learning, to motivate students and to offer feedbacks and directions to

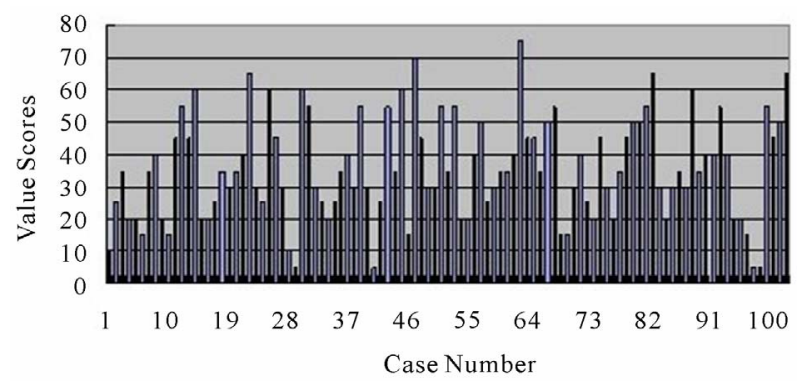

Figure 1.

Students' scores of the test paper. 
Table 1.

Choices in the questionnaire.

\begin{tabular}{ccccccccc}
\hline \multirow{2}{*}{ Item 1 } & \multicolumn{2}{c}{ A (Strongly Agree) } & \multicolumn{2}{c}{ B (Agree) } & \multicolumn{2}{c}{ C (Disagree) } & \multicolumn{2}{c}{ D (Strongly Disagree) } \\
\cline { 2 - 9 } & $\mathrm{N}$ & $\mathrm{P}$ & $\mathrm{N}$ & $\mathrm{P}$ & $\mathrm{N}$ & $\mathrm{P}$ & $\mathrm{N}$ & $\mathrm{P}$ \\
\hline Students' & 27 & $26.22 \%$ & 70 & $67.96 \%$ & 5 & $4.85 \%$ & 1 & $0.97 \%$ \\
Teachers' & 1 & $10 \%$ & 8 & $80 \%$ & 1 & $10 \%$ & 0 & $0 \%$ \\
\hline
\end{tabular}

Table 2.

Choices in the questionnaire.

\begin{tabular}{clccccccc}
\hline Item (Students') & \multicolumn{2}{l}{ A (Strongly Agree) } & \multicolumn{2}{c}{ B (Agree) } & \multicolumn{2}{c}{ C (Disagree) } & \multicolumn{2}{c}{ D (Strongly Disagree) } \\
\hline & $\mathrm{N}$ & $\mathrm{P}$ & $\mathrm{N}$ & $\mathrm{P}$ & $\mathrm{N}$ & $\mathrm{P}$ & $\mathrm{N}$ & $\mathrm{P}$ \\
Item 8 & 20 & $19.42 \%$ & 61 & $59.22 \%$ & 18 & $17.48 \%$ & 4 & $3.88 \%$ \\
Item 9 & 21 & $20.39 \%$ & 13 & $12.62 \%$ & 65 & $63.11 \%$ & 4 & $3.88 \%$ \\
\hline
\end{tabular}

Table 3.

Choices in the questionnaire.

\begin{tabular}{clccccccc}
\hline Item (Teachers') & A (Strongly Agree) & \multicolumn{2}{c}{ B (Agree) } & \multicolumn{2}{c}{ C (Disagree) } & \multicolumn{2}{c}{ D (Strongly Disagree) } \\
\hline \multirow{2}{*}{ Item 6 } & $\mathrm{N}$ & $\mathrm{P}$ & $\mathrm{N}$ & $\mathrm{P}$ & $\mathrm{N}$ & $\mathrm{P}$ & $\mathrm{N}$ & $\mathrm{P}$ \\
& 0 & $0 \%$ & 1 & $10 \%$ & 7 & $70 \%$ & 2 & $20 \%$ \\
\hline
\end{tabular}

Table 4.

Arrangements of English teaching in this key middle school.

\begin{tabular}{|c|c|c|}
\hline \multirow{5}{*}{ Formal Course } & Monday (2 coures) & Leading in and analyzing the structure of the text \\
\hline & Tuesday (2 coures) & Analyzing the language points in the text \\
\hline & Wednesday ( 2 coures) & Analyzing the language points in the text \\
\hline & Thursday (2 coures) & Analyzing the exercises \\
\hline & Friday ( 2 coures) & Analyzing the exercises \\
\hline Morning self-study & Twice or Three Times for a Week & Instructing students to read, listen and distinguish some difficult grammars \\
\hline Evening self-study & Once or Twice for a week & Instructing students to do the exercise \\
\hline
\end{tabular}

teaching. A good testing system has positive effects on English teaching and learning.

At present, for senior high school students, the NMET is considered as the most important test. It is the most essential factor in English learning for senior high school students in China, guiding the content of English learning (Zhao, 2008). NMET involves listening, grammar, cloze, reading and writing. Tables 7 and 8 show that the proportion of Chinese culture in cloze and reading part is rather low, compared with the target culture. Proportion of Chinese culture in reading is $4 \%$, while the target culture is $76 \%$. The proportion of Chinese culture of Chinese culture in cloze is $0 \%$, while the target culture is $60 \%$.

Item 10 teachers' questionnaire and item 10 in students' questionnaire involve this question. Table 9 indicates that most of the teachers and students consider the main reason they ignore the Chinese culture in English teaching and learning is that there is little content about it in examination.
Therefore, NMET can't avoid being blamed on for students' poor ability of expressing Chinese culture in English.

In a word, the inadequate construction on Chinese culture in English class, the limited teaching material in English textbooks, and the NMET which has no emphasis on English versions of Chinese culture are responsible for the existence of the aphasia of Chinese culture.

\section{Suggested Solutions}

\section{Changes on Cultural Teaching Method}

\section{Contrastive Method}

In the aspect of cultural studies in foreign language education, the scholars in Euramerican countries have done a lot of empirical studies which provide us Chinese plenty of classical examples and suggestions. Kramsch claims that cultural teach- 
Table 5.

Choices in the questionnaire.

\begin{tabular}{ccccccccc}
\hline Items (Teachers') & \multicolumn{2}{c}{ A (Strongly Agree) } & \multicolumn{2}{c}{ B (Agree) } & \multicolumn{2}{c}{ C (Disagree) } & \multicolumn{2}{c}{ D (Strongly Disagree) } \\
\hline & $\mathrm{N}$ & $\mathrm{P}$ & $\mathrm{N}$ & $\mathrm{P}$ & $\mathrm{N}$ & $\mathrm{P}$ & $\mathrm{N}$ & $\mathrm{P}$ \\
Item 7 & 0 & $0 \%$ & 1 & $10 \%$ & 6 & $60 \%$ & 3 & $30 \%$ \\
Item8 & 0 & $0 \%$ & 0 & $0 \%$ & 4 & $40 \%$ & 6 & $60 \%$ \\
\hline
\end{tabular}

Table 6.

Culture arrangement in NSEFC.

\begin{tabular}{cccc}
\hline Culture Selection & Example & N & P \\
\hline Target Culture & Puzzles in Geography (Book 5, Unit 2, Reading A) & 9 & $36 \%$ \\
Chinese Culture & A Pioneer for All People (Book 4, Unit 2, Reading A) & 3 & $12 \%$ \\
Comparative Culture & Festivals Around the World(Book 3, Unit 1, Reading A) & 2 & $8 \%$ \\
Non-target and Non-Chinese Culture & A Student of African Wildlife (Book 4, Unit 1, Reading A) & 4 & $16 \%$ \\
Common Culture & First Aid for Burns (Book 5, Unit 5, Reading A) & 7 & $28 \%$ \\
\hline
\end{tabular}

Table 7.

Cultures in reading part of NMET I papers (2006-2010).

\begin{tabular}{|c|c|c|c|c|c|c|}
\hline \multirow{2}{*}{ Reading } & \multicolumn{2}{|c|}{ Chinese Culture } & \multicolumn{2}{|c|}{ Target Culture } & \multicolumn{2}{|c|}{ Common Culture } \\
\hline & $\mathrm{N}$ & $\mathrm{P}$ & $\mathrm{N}$ & $\mathrm{P}$ & $\mathrm{N}$ & $\mathrm{P}$ \\
\hline 2006 & 1 (D) & $20 \%$ & 3 (BCE) & $60 \%$ & 1 (A) & $20 \%$ \\
\hline 2007 & 0 & $0 \%$ & 4 (ACDE) & $80 \%$ & 1 (B) & $20 \%$ \\
\hline 2008 & 0 & $0 \%$ & 4 (A B D E) & $80 \%$ & $1(\mathrm{C})$ & $20 \%$ \\
\hline 2009 & 0 & $0 \%$ & 3 (B C E) & $60 \%$ & 2 (A D) & $40 \%$ \\
\hline 2010 & 0 & $0 \%$ & 5 (A B C D E) & $100 \%$ & 0 & $0 \%$ \\
\hline Total & 1 & $4 \%$ & 19 & $76 \%$ & 5 & $20 \%$ \\
\hline
\end{tabular}

Note: “A, B, C, D, E” respectively stands for “passage A, passage B, passage C, passage D, passage E” in NMET I.

Table 8.

Cultures in cloze part of NMET I papers (2006-2010).

\begin{tabular}{|c|c|c|c|c|c|c|}
\hline \multirow{2}{*}{ Cloze } & \multicolumn{2}{|c|}{ Chinese Culture } & \multicolumn{2}{|c|}{ Target Culture } & \multicolumn{2}{|c|}{ Common Culture } \\
\hline & $\mathrm{N}$ & $\mathrm{P}$ & $\mathrm{N}$ & $\mathrm{P}$ & $\mathrm{N}$ & $\mathrm{P}$ \\
\hline 2006 & 0 & $0 \%$ & 0 & $0 \%$ & 1 & $100 \%$ \\
\hline 2007 & 0 & $0 \%$ & 1 & $100 \%$ & 0 & $0 \%$ \\
\hline 2008 & 0 & $0 \%$ & 0 & $0 \%$ & 1 & $100 \%$ \\
\hline 2009 & 0 & $0 \%$ & 1 & $100 \%$ & 0 & $0 \%$ \\
\hline 2010 & 0 & $0 \%$ & 0 & $0 \%$ & 1 & $100 \%$ \\
\hline Total & 0 & $0 \%$ & 2 & $40 \%$ & 3 & $60 \%$ \\
\hline
\end{tabular}

Table 9.

Choices in the questionnaire.

\begin{tabular}{ccccccccc}
\hline \multirow{2}{*}{ Items } & \multicolumn{2}{c}{ A (Strongly Agree) } & \multicolumn{2}{c}{ B (Agree) } & \multicolumn{2}{c}{ C (Disagree) } & \multicolumn{2}{c}{ D (Strongly Disagree) } \\
\cline { 2 - 9 } & $\mathrm{N}$ & $\mathrm{P}$ & $\mathrm{N}$ & $\mathrm{P}$ & $\mathrm{N}$ & $\mathrm{P}$ & $\mathrm{N}$ & $\mathrm{P}$ \\
\hline Item 13 in Teachers' & 7 & $70 \%$ & 3 & $30 \%$ & 0 & $0 \%$ & 0 & $0 \%$ \\
Item 16 in Students' & 23 & $22.33 \%$ & 57 & $55.34 \%$ & 7 & $6.80 \%$ & 16 & $15.53 \%$ \\
\hline
\end{tabular}


ing should be integrated in foreign language teaching (Kramsch, 1993). Thus, Chinese culture should be added in the language teaching. Meanwhile, in the process of introducing western cultures, comparing and contrasting with the Chinese culture is necessary. This is called contrastive method which is an important device in intercultural teaching. Through contrasting and comparing, Chinese students of English can have a cognitive awareness of cultural differences and similarities between the two languages. A good use of the similarities between the languages could help students express the idea more naturally and idiomatically. Meanwhile, differences can increase their cultural awareness.

For instance, when students learn Unit 3, A Taste of English Humor in New Senior high school English for China Book 4, a contrast study could be made between the English humor and the Chinese humor. It may be done as the Table 10 shows:

By doing this activity, students could learn something about both Chinese and English humors. Integration of two cultures could finally be achieved and stimulate students' potential ability.

\section{Translation Method}

Now that western culture input is holding a dominant role in English textbooks and tests. Chinese English teachers can translate some English to Chinese proverbs or idioms. A typical example of this is that: East or west, home is the best. In Chinese, it equals to 金窝银窝不如自己的狗窝.

While translate the proverbs or idioms, Chinese English teachers are suggested to make comparison between the English expression and the Chinese one to deepen the understanding the similarities and differences between them.

\section{Suggestions on Textbooks}

English textbooks play a major and central part in English learning and teaching. They are the reflection of teaching syllabus and the essential media for teachers and schools to achieve the aims of teaching. According to the above reason analysis, it is found that Chinese cultures in textbooks are not adequate. Therefore, adjustment and improvement should be made on English textbooks. It's wise to increase Chinese culture in English textbooks, which can make teachers and students pay much more attention. It can also create more chances for students to arrive at a better understanding of both Chinese can western cultures.

\section{Changes on Evaluation}

Evaluation plays an important role in English curriculum.
Evaluation can make the teachers acquire the feedback of the students' English study (Richards, 2000). A test may have either a harmful or beneficial effect on English teaching and learning. A good English test should have a positive effect on the teaching and learning of English.

Since there are no planed and systematic items to test Chinese cultures in English tests, the content of English test items should be adjusted. Adequate attention should be given to testing students' ability of expressing Chinese culture in English by adding some special items in the tests, which can exert a positive effect on intercultural communication.

If there are no reforms about evaluation, it will be difficult to realize the objectives of Chinese culture teaching. Thus, according to the features of Chinese culture teaching, some new forms or contents of NMET should be designed. Otherwise, Chinese cultural teaching can't be paid enough attention and is difficult to carry out. Therefore, making sure the evaluation system complete is essential for Chinese cultural teaching.

\section{Conclusion}

In senior high school English teaching in China, teachers attach much importance to words, grammatical points and idioms in order to enhance students' basic linguistic competence and to score high in NMET. However, this hinders students' sociocultural competence. The result is that although students have studied years of English they are unable to express Chinese culture in English. This makes the intercultural communication unsatisfactory and unsuccessful. Through the investigation with quantitative and qualitative methods, this paper finds out that the aphasia of Chinese culture does exist among senior high school students and there are three main factors that are responsible for this phenomenon. They are: 1) lack of introduction on Chinese culture in English class; 2) inadequacy of Chinese culture in textbooks; 3) no emphasis on Chinese culture in English test.

To balance the target language learning and native language learning, this paper proposes three suggestive solutions: 1) making changes on cultural teaching method; 2) adding more Chinese culture in English to the textbooks; 3) revising NMET to realize the objectives of Chinese cultural teaching.

In a word, this paper makes empirical study of the aphasia of Chinese culture and provides suggestive solutions to the problem to improve the current culture teaching in senior high school English class.

Nevertheless, this paper is not without its limitations. Firstly, the test in the investigation does not seem large enough. In

Table 10.

Humors in China and western countries.

\begin{tabular}{|c|c|c|c|c|c|}
\hline & & 1 & 2 & 3 & 4 \\
\hline S & & Implicit \& Restraint & Profound cultural accumulation & Enlightened & Understated \& quick-witted \\
\hline \multirow{2}{*}{$\mathrm{D}$} & Chinese & laughing at others & Clever people doing stupid things & $\begin{array}{c}\text { Emphasizing } \\
\text { expression of words }\end{array}$ & $\begin{array}{c}\text { Example: } \\
\text { My Own Swordsman }\end{array}$ \\
\hline & Western & Laughing at themselves & Stupid people doing stupid things & $\begin{array}{l}\text { Emphasizing exaggerated } \\
\text { expressions and gestures }\end{array}$ & Example: Mr. Bean \\
\hline
\end{tabular}

Note: "S" stands for similarities, "D" stands for differences. 
addition, the investigation is only in the written form but leaves the oral test aside. Last, the solutions suggested in this paper are based on the investigation but have not been under the test of the culture teaching in the real class.

Thus, the research is only done partly in this paper, how to train senior high school students to achieve successful intercultural communication demands further study.

\section{Acknowledgements}

The author is greatly indebted to the subjects for their friendly and honest participation in this study. Special thanks to her supervisor Prof. Lisheng Li, whose instruction and encouragement has contributed greatly to the completion of the paper. The author is also grateful for Prof. Jieyun Duan for her connection with the key middle school, helpful suggestions and encouragement. Many thanks to Mr. Bo Zhao, the PhD. candidate of the Chinese academy of sciences for his great encouragement. Sincere gratitude goes to the anonymous reviewer for his/her valuable revising suggestions on this paper.

\section{References}

Cao, S. Q. (1996). Aphasia of Chinese literary criticism and morbid culture. Literary Contend, 2, 50-58.

Cong, C. (19 October 2000). "Aphasia of Chinese culture”: The limitation of English teaching. Guangming Daily, 10-19.

Deng, W. Y., \& Ao, F. (2005). Analysis of English major students' Chinese culture aphasia. Journal of Bingtuan Education Institute, 4, 58-61.

Gao, S. R. (2006). Aphasia (2nd ed.). Beijing: Peking University Medical Press.

Gao, Y. H. (2001). Foreign language learning " $1+1>2$ ". Beijing: Peking University Press.
Hudson, R. A. (2007). Sociolinguistics (2nd ed.). Beijing: Foreign Language and Research Press.

Kramsch, C. (1993). Context and culture in foreign language teaching. Oxford: Oxford University Press.

Liu, C. J. (2003). The integration of foreign culture and native culture into FLT. Foreign Language World, 4, 14-18.

Liu, Y. G., \& He, G. D. (2010). Probe into localization of foreign language teaching in China under globalization. Computer-Assisted Foreign Language Education in China, 7, 247-249.

Ministry of Education of the People's Republic of China (2003). New English curriculum criteria for senior school. Beijing: People's Education Press.

Richards, J. C. (2000). Curriculum development in language teaching. New York: Cambridge University Press.

Samovar, L. A., Porter, E. P., \& McDaniel, E. R. (2009). Communication between cultures. Beijing: Peking University Press.

Xiao, L. F., Xiao, D., Li, L., \& Song, Y. W. (2010). A study of the "Chinese culture aphasia" in present English education in Chinese higher education. Foreign Language Learning: Theory and Practice, 1, 39-46.

Zhang, L. Y. (2009). Aphasia of Chinese culture in English teaching in middle school. MA Thesis, Chongqing: Southwest University.

Zhao, L. Z. (2008). The reforms of culture test in NMET. Tianjin Education, 10, 44.

Zhang, Q. X. (2009). Misunderstandings of international communication in foreign language teaching. Theory Learning, 19, 247-249.

Zhang, G. C., \& Zhang, H. Y. (2007). The impact of English globalization on cultural teaching and learning in senior high school English. Curriculum, Teaching Material and Method, 6, 49-52 .

Zhang, W., Mi, J. Q., \& Sun, B. (2009). "Aphasia of Chinese culture” in college English teaching and the countermeasures. Journal of Shenyang Agricultural University (Social Science Edition), 4, 457460.

Zhang, W., Mi, J. Q., \& Yin, L. (2008). Investigation on non-English major students' aphasia of Chinese culture. Journal of Jiangnan University (Education Sciences), 1, 39-42. doi:10.1631/jzus.2000.0039 


\section{Appendix I. Test Paper}

\section{Test on Aphasia of Chinese Culture in Senior High School English}

Note: Please translate the following Chinese independently. If you don't know the answers, you may not write down anything. Don't consult the dictionaries or classmates. The results are only used for the study of foreign language teaching.

Translate the following Chinese into English:

1. 火锅

2. 拜年

3. 中秋节

4. 功夫

5. 孔子

6. 市长

7. 麻将

8. 电影《唐山大地震》

9. 长城

10. 《红楼梦》

11. 上海世博会

12. 豆腐

13. 梅花

14. 国画

15. 压岁钱

16. 团支部书记

17. 筷子

18. 过桥米线

19. 瓷器

20. 高考

\section{Appendix II. Questionnaire}

\section{Questionnaire on Aphasia of Chinese Culture in Senior High School English Teaching (Students')}

School:

Grade:

\section{Dear class,}

Nice to meet you!

Thanks for your participation in this survey. The purpose of this survey is to investigate the aphasia of Chinese culture in senior English teaching. Please carefully read and respond to each question. Of course, all data collected here will be only used for this study, and your questionnaire will be kept properly.

Thank you for your cooperation!

Multiple Choices

1. I feel it difficult to express Chinese culture in English.
A strongly agree
B agree
C disagree
D strongly disagree
2. Culture is equal.
A strongly agree
B agree
C disagree
D strongly disagree

3. Language learning is closely related to the culture learning.
A strongly agree
B agree
C disagree
D strongly disagree

4. It's unnecessary to learn Chinese culture in English class for what I study is English.
A strongly agree
B agree
C disagree
D strongly disagree

5. When I communicate with foreigners, it's necessary to introduce the excellent Chinese culture.
A strongly agree
B agree
C disagree
D strongly disagree

6. I really hope that I can express Chinese culture in English in English class to motivate my English learning.
A strongly agree
B agree
C disagree
D strongly disagree

7. I learn the knowledge of culture mainly by the textbooks.
A strongly agree
B agree
C disagree
D strongly disagree

8. The teacher often teach the western culture when he or she analyzes the text.
A strongly agree
C disagree
B agree

9. In the English class, the teacher also often introduces some Chinese culture.
A strongly agree
B agree
C disagree
D strongly disagree

10. The reason why the English expression of Chinese culture is ignored is that there are few points in NMET papers.
A strongly agree
B agree
$\mathrm{C}$ disagree
D strongly disagree

\section{Appendix III}

\section{Questionnaire on Aphasia of Chinese Culture in Senior High School English Teaching (Teachers')}

Dear teachers,

Nice to meet you!

Thanks for your participation in this survey. The purpose of this survey is to investigate the aphasia of Chinese culture in senior high school English teaching. All the data collected here will be only used for this study, and your questionnaire will be kept properly.

Thank you for your cooperation!

Multiple Choices

1. Students often can't express Chinese culture in English.
A strongly agree
B agree
C disagree
D strongly disagree

2. It's not proper to introduce Chinese cultures in English class.
A strongly agree
B agree
C disagree
D strongly disagree

3. Learning Chinese culture has little influence on English learning.
A strongly agree
B agree
$\mathrm{C}$ disagree
D strongly disagree

4. it's not important for students to develop the ability of expressing Chinese culture in English.
A strongly agree
B agree
C disagree
D strongly disagree

5. It's necessary for students to introduce Chinese excellent 
culture when they communicate with foreigners.

$\begin{array}{ll}\text { A strongly agree } & \text { B agree } \\ \text { C disagree } & \text { D strongly disagree } \\ 6 . \text { I often introduce Chinese culture in English teaching }\end{array}$

ture and Chinese culture.

A strongly agree B B agree

C disagree D strongly disagree

9. I often find the materials are inadequate when teaching culture.
A strongly agree
B agree
C disagree
D strongly disagree

7. The current textbooks can satisfy my culture teaching.
A strongly agree
B agree
C disagree
D strongly disagree
8. The current textbooks have contained enough target cul-

10. The reason why the English expression of Chinese culture is ignored is that there are few points in NMET papers.
A strongly agree
B agree
C disagree
D strongly disagree 